\title{
Synthesis of nano-sized mesoporous silicas with metal incorporation
}

\author{
Man-Chien Chao ${ }^{\mathrm{a}}$, Hong-Ping Lin ${ }^{\mathrm{b}, *}$, Chung-Yuan Mou ${ }^{\mathrm{a}}$, \\ Bo-Wen Cheng ${ }^{\mathrm{c}}$, Chi-Feng Cheng ${ }^{\mathrm{c}}$ \\ ${ }^{a}$ Department of Chemistry, National Taiwan University, Taipei 106, Taiwan \\ ${ }^{\mathrm{b}}$ Department of Chemistry, National Cheng Kung University, Tainan 701, Taiwan \\ ${ }^{\mathrm{c}}$ Department of Chemistry, Chung-Yuan Christian University, Chung-Li 320, Taiwan \\ Available online 25 September 2004
}

\begin{abstract}
The metal oxide-incorporated or -grafted mesoporous silica nanoparticles and nanotubes have been prepared efficiently via a two-step synthetic process, which includes a pre-hydrolysis of the TEOS and metal alkoxides or salts in acidic solution $(\mathrm{pH}<1.0)$, and fast cocondensation of silica, metal oxides and surfactant in alkaline ammonia solution ( $\mathrm{pH}$ 8.0-9.0). Because the presence of the cationic surfactant and a proper $\mathrm{pH}$ range could make the silica condensation fast enough to match a relatively quick metal-oxide condensation, various metal oxides (e.g. Al-, Ti-, V-, Zr-, Fe-oxides) can be homogeneously incorporated into the silica framework or grafted on the silica surface. The XRD, reflectance UV-vis and FT-IR spectrometry and solid state NMR have been performed to further identify the successful incorporation and grafting of metal oxides. The metal oxides-incorporated mesoporous silica nanotubes or nanoparticles with high surface area, large mesoporosity and textural porosity can be considered as a capable catalyst of high connectivity and accessibility. The Al-incorporated mesoporous silica nanoparticles show higher catalytic activity toward the cumene-cracking reaction than the typical mesoporous aluminosilicate.
\end{abstract}

(C) 2004 Elsevier B.V. All rights reserved.

Keywords: Mesoporous silica nanoparticles; Tubules-within-tubule; MCM-41

\section{Introduction}

Silica-based mesoporous materials with a tunable pore size $(1-30.0 \mathrm{~nm})$ and a large surface area $\left(500-1000 \mathrm{~m}^{2} / \mathrm{g}\right)$ have attracted intense interest because of their high potential as catalysts or catalytic supports [1,2]. Consequently, many successful synthetic methods have been developed to prepare mesoporous silica with different forms and isomorphous substitution of heteroelements into a silica framework for obtaining high-performance catalysts or supports [3-6]. However, few reports have focused on the accessibility or connectivity of the silica-based mesoporous silica catalysts, which are also the determining factors on the efficiency of the catalysts [7].

\footnotetext{
* Corresponding author. Tel.: +886 6 2757575x65342; fax: +886 62740552 .

E-mail address: hplin@mail.ncku.edu.tw (H.-P. Lin).
}

To increase the accessibility of the mesoporous catalyst, there exist two strategies for improving the connectivity of the nano-channels. One is to introduce the void-detects into the mesoporous matrix, for example in the tubules-within-tubule (TWT) MCM-41 aluminosilicates [8,9]. We found that the TWT aluminosilicate is a better support for iron oxides toward dehydrogenation of ethylbenzene because of their higher channel connectivity. The other way is to reduce the particle size of the mesoporous materials. Pauly et al. [10] used a neutral alkylamine as mesostructural template to obtain the Al-substituted HMS mesoporous catalyst in an ethanol- $\mathrm{H}_{2} \mathrm{O}$ solution. Because of the smaller particle sizes $(<200 \mathrm{~nm})$, the Al-substituted HMS shows a higher catalytic activity for the alkylation of 2,4-di-tert-butylphenol with cinnamyl alcohol than the Al-incorporated MCM-41 in micron-size.

Since only incorporating the metal $\mathrm{Al}$ can effectively promote the formation of void-defects in TWT aluminosilicate [8], reducing the particle size of the 
mesoporous materials is an attractive way to improve transport in the nano-channel system. Although some previous reports provide the synthetic methods to prepare the nanosized mesoporous materials, most of them focus only on the pure-silica ones [11-16]. A synthetic method for preparing a mesoporous system with composition flexibility and designed catalytic properties is much desired.

Both kinetic and thermodynamic aspects determine the morphologies of the surfactant-silica mesostructures [17,18]. Basically in making the organic-inorganic hybrids, one needs to adjust the interaction strength between the organic templates and inorganic species in order to modify the rates of hydrolysis and condensation of the inorganic species. It is known that the interactions between the silica species and quaternary ammonium surfactants $\left(\mathrm{S}^{+}\right)$are dependent on the $\mathrm{pH}$ value [6]. Under acidic conditions $(\mathrm{pH}<2.0)$, even with the fast hydrolysis of the inorganic precursors (TEOS, or metal alkoxides), an induction period is required to obtain the silica-surfactant precipitate because of the weak hydrogen bonding $\left(\mathrm{S}^{+} \mathrm{X}^{-} \cdots \mathrm{I}^{0}\right)$ between silica species and surfactant. Moreover, the acidic solution can prevent the fast condensation of the metal oxides [19]. In contrast, in alkaline medium ( $\mathrm{pH}>7.0)$, small silica oligomers can bind tightly with surfactant via the strong electrostatic force $\left(\mathrm{S}^{+} \mathrm{I}^{-}\right)$which induces fast silica condensation $[6,20]$ to exceed the rapid self-condensation of the metal oxides in alkaline solution. Thus, an ideal co-condensation of silica with different metal alkoxides may be achieved via a special two-step process involving hydrolysis of inorganics in acidic media and fast condensation in alkaline ammonia aqueous solution. By a careful design of the nucleation and growth of the surfactantsilica self-assemble, nano-sized mesoporous metallosilicates $(<100 \mathrm{~nm})$ may be conveniently obtained.

\section{Experimental}

\subsection{Materials}

The silica source is tetraethyl orthosilicate (TEOS, Acrôs). The source of aluminum-, titanium-, vanadium-, zirconium-, and iron-oxides are, aluminum isopropoxide (98\%, Acrôs), titanium(IV) isopropoxide (98\%, Acrôs), zirconium(IV) isopropoxide (70 wt.\% in 1-propanol, Aldrich), vanadyl sulfate hydrate $\left(\mathrm{VOSO}_{4} \cdot x \mathrm{H}_{2} \mathrm{O}, 99.9 \%\right.$, Aldrich), and iron(III) chloride (98\%, Acrôs), respectively. The templating agent is cetyltrimethylammonium bromide $\left(\mathrm{C}_{16} \mathrm{TMAB}\right)$ purchased from Acrôs. The ammonia aqueous solution (28-30 wt.\% $\mathrm{NH}_{3}$ ), hydrochloric acid and nitric acid are from Acrôs. All these chemicals were used directly without further purification.

\subsection{Synthesis}

The basic concept of the synthetic procedure for the metal oxide-incorporated mesoporous silica nanoparticles or nanotubes is schematically described in Eq. (1):

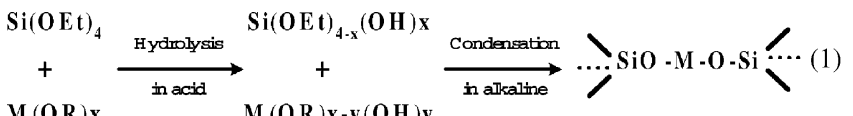

$$
\begin{aligned}
& \mathrm{M}(\mathbf{O R}) \mathrm{x} \quad \mathrm{M}(\mathrm{OR}) \mathrm{x}-\mathrm{y}(\mathbf{0 H}) \mathrm{y}
\end{aligned}
$$

The first step is to prepare a clear aqueous solution of hydrolyzed inorganic precursor mixtures (TEOS and metal alkoxides or salts) and $\mathrm{C}_{16}$ TAMB surfactant at low $\mathrm{pH}$. A desired amount of $\mathrm{C}_{16} \mathrm{TMAB}$, TEOS, and metal alkoxides was added into a highly acidic solution $(\mathrm{pH} \sim 0.0)$ and stirred for a period of 6-12 min at room temperature. In the second step, a fast co-condensation reaction was achieved in ammonia aqueous solution. The acidic solution containing surfactant and hydrolyzed inorganic species was poured quickly into a $300 \mathrm{ml} 0.125 \mathrm{M}$ ammonia solution and a colloid suspension gel solution was obtained immediately; and the final $\mathrm{pH}$ value was located in the range of 8.0-9.0 by a proper control on the ratio of acid/ammonia. The chemical composition of the gel solution in molar ratio is 1.0 $\mathrm{C}_{16}$ TMAB:4.5TEOS:(0.0-1.8) metal alkyloxides or salt$\mathrm{s}: 24.0 \mathrm{acid}: 158.0 \mathrm{NH}_{4} \mathrm{OH}: 11076.0 \mathrm{H}_{2} \mathrm{O}$. The acid source is $\mathrm{HNO}_{3}$ or $\mathrm{HCl}$. Filtration, washing and drying at $100{ }^{\circ} \mathrm{C}$ gave the products. A $560{ }^{\circ} \mathrm{C}$ calcination in air was performed to remove the organic templates. Detailed studies of controlling factors in the synthetic process will be reported elsewhere.

\subsection{Characterization}

X-ray powder diffraction (XRD) patterns were collected on a Scintag X1 diffractometer using $\mathrm{Cu} \mathrm{K} \alpha$ radiation $(\lambda=$ $0.0154 \mathrm{~nm}$ ). The $\mathrm{N}_{2}$ adsorption-desorption isotherms were obtained at $77 \mathrm{~K}$ on a Micromeritics ASAP 2010 apparatus. The scanning electron microscopy (SEM) and transmission electron micrographs (TEM) were taken on an S-800 (Hitachi) operated at an accelerating voltage of $20 \mathrm{keV}$ and an H-7100 (Hitachi) operated at $100 \mathrm{keV}$, respectively. The ${ }^{27} \mathrm{Al}$ MAS NMR spectra were recorded with a 200-s pulse delay on a Bruker MSL 300 NMR spectrometer. The reflectance UV-vis spectra were measured with a Hitachi U3010 double beam spectrophotometer. The IR spectra have been collected on a FT-IR spectrometer by coaddition of 16 scans at a $4 \mathrm{~cm}^{-1}$ resolution.

\section{Results and discussion}

Fig. 1A shows the XRD of the various calcined metal oxide-incorporated or grafted mesoporous silicas (denoted as $\mathrm{M}-\mathrm{MS} ; \mathrm{M}=\mathrm{Al}, \mathrm{Ti}, \mathrm{V}, \mathrm{Zr}, \mathrm{Fe}$ ) synthesized from $\mathrm{C}_{16}$ TMAB-TEOS- $\mathrm{HCl}$-ammonia- $\mathrm{H}_{2} \mathrm{O}$ components with the silica/metal oxide ratio $=20.0$. At the low-angle range of $2-5^{\circ}$, one can find two broad peaks, which can be assigned to the disordered mesostructure. No apparent peaks at a high angle of $30-50^{\circ}$ were observed indicating that no separate phase of metal oxides was formed during the 

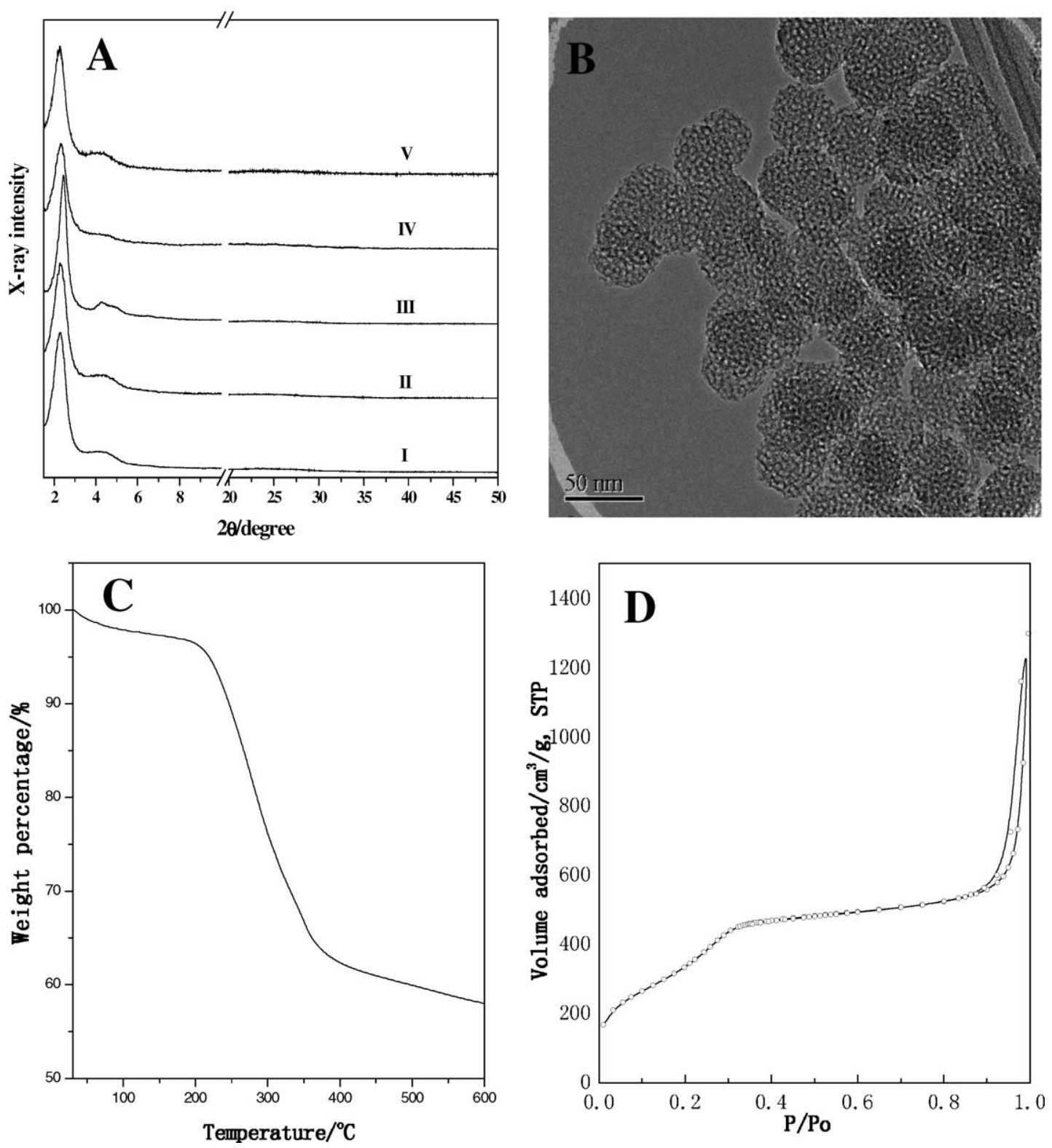

Fig. 1. (A) The XRD patterns of the different metal oxide-incorporated or -grafted mesoporous silica of the Si/metal molar ratio $=20$ synthesized from $\mathrm{C}_{16}$ TMAB-metal alkoxides or salts-TEOS-HCl-ammonia- $\mathrm{H}_{2} \mathrm{O}$ compositions. Sample I: aluminum oxide; sample II: titanium oxide; sample III: zirconium oxide; sample IV: vanadium oxide; sample V: iron oxide. (B) HRTEM micrograph of the Al-incorporated mesoporous silica nanoparticles. (C) The TGA diagram of the as-synthesized Al-incorporated mesoporous silica nanoparticles. (D) The $\mathrm{N}_{2}$ adsorption-desorption isotherm of the calcined Al-incorporated mesoporous silica nanoparticles.

synthetic and calcination processes. Fig. 1B displays the representative HRTEM images of the Al-substituted mesoporous silica (Al-MS). It is obvious that the Al-MS sample is in fine-particle form of nanometer size, and these fine particles' sizes are about $30-40 \mathrm{~nm}$. Parallel to the results of XRD patterns, the mesostructure is wormhole-like. The thermogravimetric analysis (TGA) diagram of the assynthesized Al-MS nanoparticles reveals that the weightloss between 200 and $300{ }^{\circ} \mathrm{C}$ is about $40-45$ wt. \% (Fig. 1C). With the analysis of $\mathrm{N}_{2}$ adsorption-desorption isotherms, the Al-MS nanoparticles show a capillary condensation at $P /$ $P_{0}$ around 0.35 as the typical MCM-41 mesoporous aluminosilicate, and an extra large adsorption at $P / P_{0}$ at about 0.9 . The appearance of the additional adsorption at $P /$ $P_{0} \sim 0.9$ is ascribed to the filling of the textural mesoporosity, which results from the intergrowth or aggregation of the fundamental nanoparticles [10,21]. The Al-MS nanoparticles have a high surface area of about $1000 \mathrm{~m}^{2} / \mathrm{g}$. The other M-MS nanoparticles have similar physical properties to those of Al-MS nanoparticles. The data are listed in Table 1. All M-MS samples have a high $V_{\text {text }} / V_{\text {meso }}$ ratio. According to these results, the metal oxideincorporated or grafted mesoporous silica nanoparticles can be easily synthesized by using the two-step method. 
Table 1

The physical properties of the different metal oxide-incorporated mesoporous silicas synthesized from $\mathrm{C}_{16}$ TMAB-TEOS-metal alkoxides or salts$\mathrm{HCl}-$ ammonia- $\mathrm{H}_{2} \mathrm{O}$ compositions at $\mathrm{pH} 8.0-9.0$ at $30{ }^{\circ} \mathrm{C}$

\begin{tabular}{lllll}
\hline Sample & $S_{\text {BET }}\left(\mathrm{m}^{2} / \mathrm{g}\right)$ & $V_{\mathrm{p}}\left(\mathrm{cm}^{3} / \mathrm{g}\right)^{\mathrm{a}}$ & Pore size $(\mathrm{nm})$ & $V_{\text {text }} / V_{\text {meso }} \mathrm{b}$ \\
\hline Al-MS(20) & 1089 & 1.95 & 2.1 & 1.83 \\
Al-MS(40) & 1156 & 1.17 & 2.1 & 1.12 \\
Zr-MS(20) & 1056 & 1.33 & 2.4 & 1.34 \\
Zr-MS(40) & 1155 & 1.59 & 2.3 & 1.29 \\
Ti-MS(20) & 1117 & 1.48 & 2.2 & 1.63 \\
Ti-MS(40) & 1151 & 1.70 & 2.2 & 1.68 \\
V-MS(20) & 1126 & 1.71 & 2.1 & 1.44 \\
Fe-MS(20) & 1028 & 1.66 & 2.2 & 1.75 \\
\hline
\end{tabular}

${ }^{\text {a }}$ Pore volume $\left(V_{\mathrm{p}}\right)$ obtained from $\mathrm{N}_{2}$ volume adsorbed at $P / P_{0}=0.99$.

${ }^{\mathrm{b}} V_{\text {meso, }}$, framework pore volume obtained from the volume of $\mathrm{N}_{2}$ adsorbed at $P / P_{0}=0.50 ; V_{\text {text }}=V_{\mathrm{p}}-V_{\text {meso }}$.

The shapes of the primary particles of M-MS are dependent on the acid source. When nitrate acid is used, the counterion $\mathrm{NO}_{3}{ }^{-}$with a stronger binding strength to quaternary ammonium surfactant than $\mathrm{Cl}^{-}$can promote the elongation of the micelles [22]. Then, the long-rod surfactant micelles induce the formation of the mesostructured nanotubes. Fig. 2A is a low-magnification TEM image of the Al-MS sample using $\mathrm{HNO}_{3}$ as acid source. Obviously, the particle shape is in nanotubes. Under a high-magnification observation (Fig. 2B), one can clearly find that the nanotubes consisted of about 10-20 nanochannels. The diameter of the Al-mesoporous silica nanotubes is less than $60 \mathrm{~nm}$, and the length is around $200 \mathrm{~nm}$ (Fig. 2B). There are four XRD peaks for this sample, indicating a well-ordered hexagonal mesostructure. Similarly, other M-MS nanotubes can also be obtained using the $\mathrm{HNO}_{3}$ as acid source. In general, we found the nanotubes get shorter with the increase of the metal-oxides content. That is because the incorporation of metal oxide would weaken the interactions of surfactant-silica. All the M-MS nanotube samples have a capillary condensation at $P / P_{0}$ at $0.30-0.35$ and a large textural (external) adsorption at $P / P_{0}$ at about 0.9 .
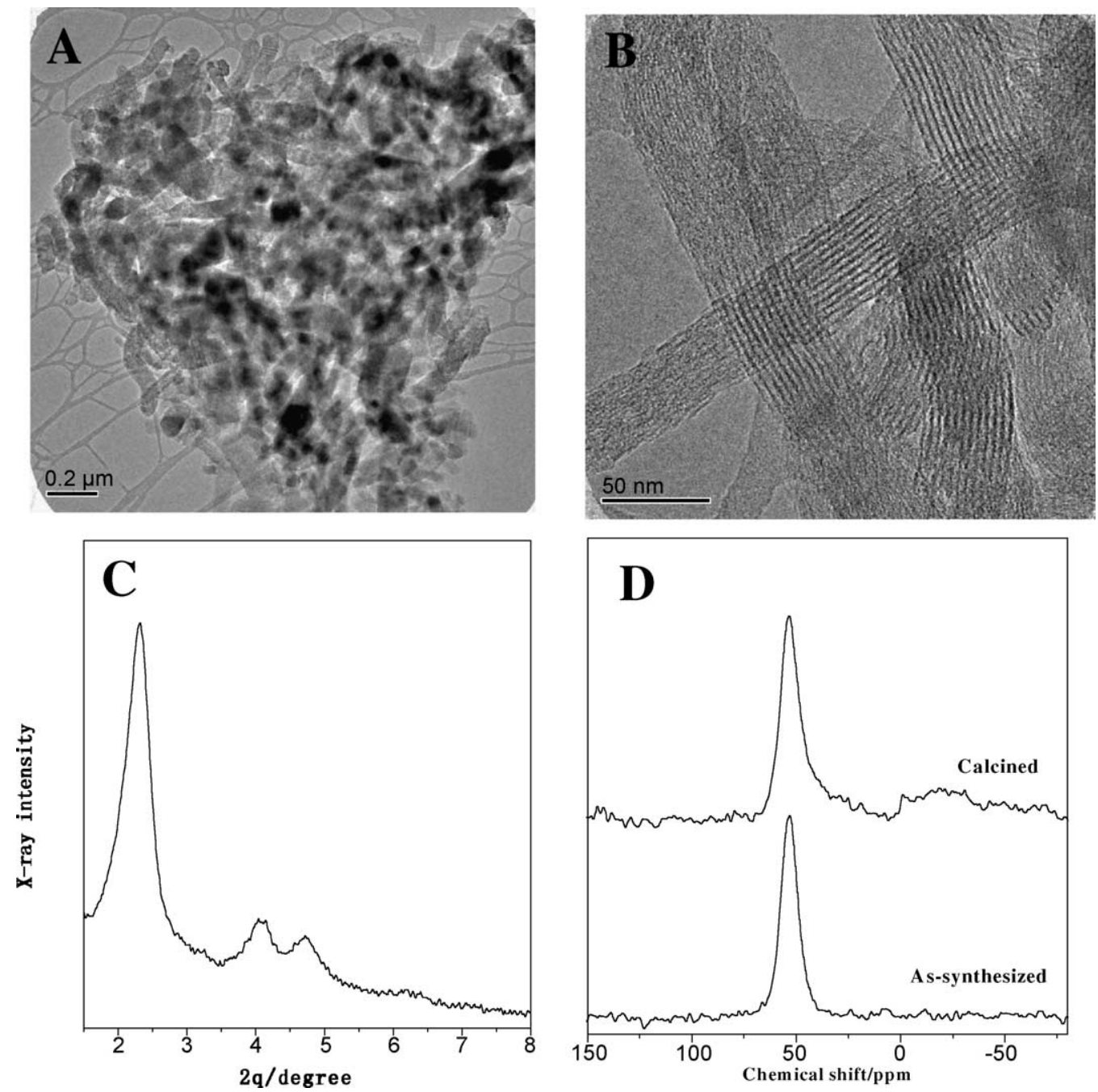

Fig. 2. (A) The low-magnification TEM image of the Al-incorporated mesoporous silica nanotubes synthesized with $\mathrm{C}_{16} \mathrm{TMAB}-\mathrm{aluminum}$ isopropoxideTEOS- $\mathrm{HNO}_{3}$-ammonia- $\mathrm{H}_{2} \mathrm{O}$ compositions. (B) The high-magnification TEM image of the sample of (A). (C) The XRD pattern of the sample of (A). (D) The

${ }^{27} \mathrm{Al}$ MAS NMR spectra of the calcined and as-synthesized samples of (A). 

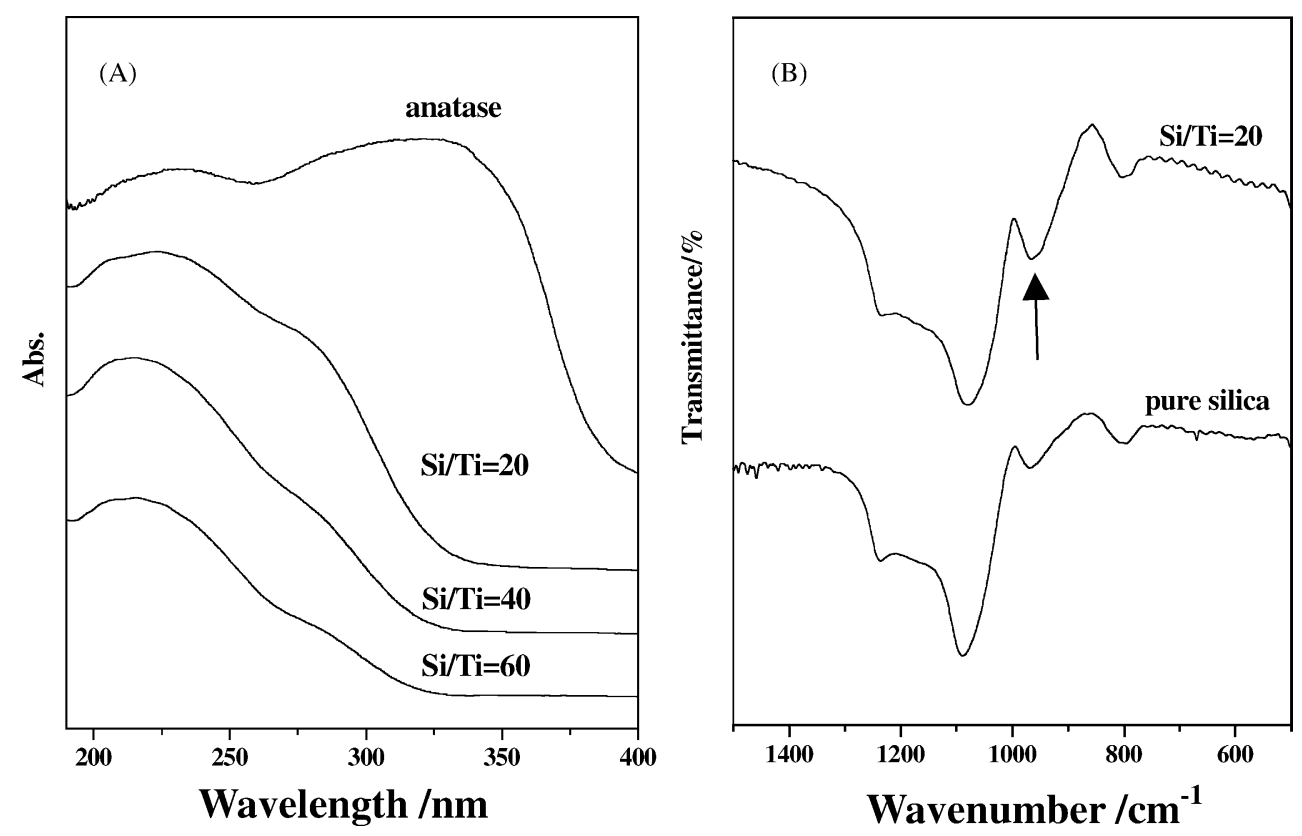

Fig. 3. (A) The reflectance UV-vis spectra of the calcined Ti-MS nanoparticle samples with different Si/Ti ratios. (B) IR spectra of calcined Ti-MS nanoparticle samples with different $\mathrm{Si} / \mathrm{Ti}$ ratios.

Next, we report on more complete characterizations on the Al-, Ti-, Zr-MS nanoparticles or nanotubes. Fig. 2D shows the ${ }^{27} \mathrm{Al}$ MAS NMR spectra of the Al-MS nanotubes with the $\mathrm{Si} / \mathrm{Al}=20$; only framework aluminum oxide (at $54 \mathrm{ppm}$ ) was detected in the as-synthesized sample, and only a little part of non-framework aluminum oxide (at $0 \mathrm{ppm}$ ) was formed after high-temperature calcination [8]. These data indicate the aluminum oxide is stably incorporated into the silica framework.

The reflectance UV-vis spectra of the Ti-MS nanoparticles with different $\mathrm{Si} / \mathrm{Ti}$ ratios were examined (Fig. 3A). The intensity of the absorption band increases inherently with the increase of the titanium content, but the spectra do not have an obvious red-shift. Compared to the bulk anatase $\mathrm{TiO}_{2}$, the Ti-MS nanoparticles have an observable highenergy band gap near $325 \mathrm{~nm}$, which confirms the absence of the bulk $\mathrm{TiO}_{2}$ particles. According to a previous report [23], the two main peaks at 215 and $270 \mathrm{~nm}$ in Ti-MS nanoparticles are assigned to titanium species in tetrahedral $\left(\mathrm{T}_{\mathrm{d}}\right)$ and octahedral $\left(\mathrm{O}_{\mathrm{h}}\right)$ coordination, respectively. The presence of the $\mathrm{O}_{\mathrm{h}}$ adsorption could be the result of the water ligation to the titanium $T_{d}$ species on or close to the channel surface during preparation. Moreover, in the IR spectra, one can clearly find that the Ti-MS nanoparticles possess a higher intensity of an absorption band at $960 \mathrm{~cm}^{-1}$ than the mesoporous pure-silica sample (Fig. 3B). The extra increase of this absorption band is reasonably attributed to the asymmetric Si-O-Ti bond, which indicates the successful grafting of titanium oxide onto the silica wall [23].

To detect the framework and extra-framework zirconium species UV-vis spectroscopy is extensively used. These $\mathrm{Zr}$ MS nanoparticles with $\mathrm{Si} / \mathrm{Zr}$ ratios of 20 and 40 synthesized by our two-step process show an absorption band at
205-215 nm (Fig. 4). This absorption band is usually attributed to ligand-to-metal charge transfer (LMCT) from an $\mathrm{O}^{2-}$ to an isolated $\mathrm{Zr}^{4+}$ ion in a tetrahedral configuration [24,25]. In comparison, the LMCT in bulk $\mathrm{ZrO}_{2}$ shifts to lower energy of about $230 \mathrm{~nm}$. The sample of high zirconium content of $\mathrm{Si} / \mathrm{Zr}$ ratio of 20 shows no bulk $\mathrm{ZrO}_{2}$ peaks, which could be regarded to a homogeneous grafting of $\mathrm{Zr}$ on the silica wall.

From these aforementioned results, the two-step method we proposed is a highly efficient way to prepare the metal oxide-incorporated or grafted mesoporous catalyst. The

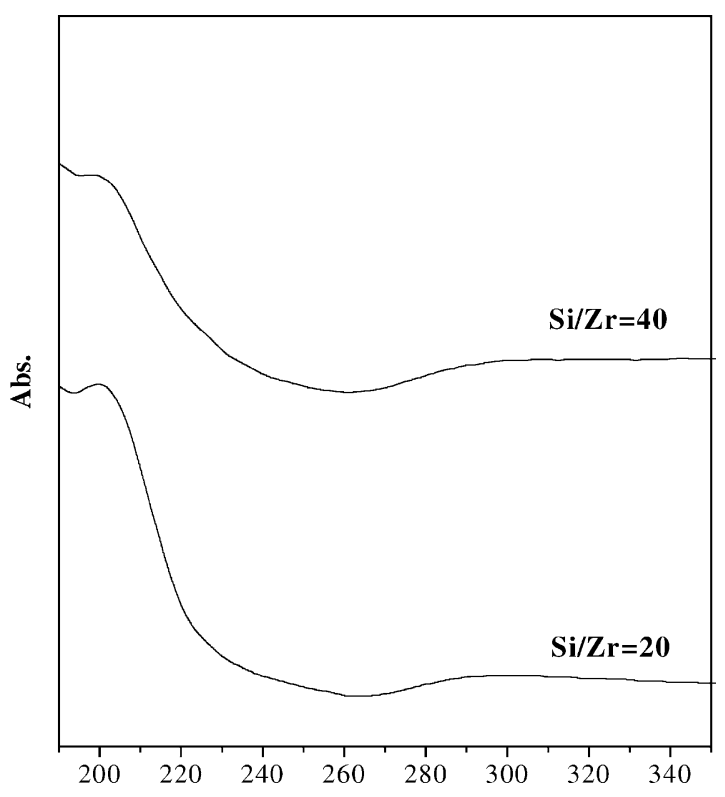

Fig. 4. The reflectance UV-vis spectra of the calcined Zr-MS nanoparticle samples with different $\mathrm{Si} / \mathrm{Zr}$ ratios. 
better transport of guest molecules in its nanopores may be examined by looking into its catalytic application. To prove the metal oxide-incorporated or grafted mesoporous silica nanoparticles or nanotubes have a higher efficiency on catalytic reactions, we used the catalytic materials in the cumene cracking reaction, which requires mesopores and strong surface acidity. We compared the catalytic activity in the Al-MS nanoparticles ( $\mathrm{Si} / \mathrm{Al}$ ratio $=20)$ and the MCM-41 aluminosilicate $(\mathrm{Si} / \mathrm{Al}=20)$ in micrometer size on the conversion of cumene. In Fig. 5, one can see that the cumene conversion for the Al-MS nanoparticles is higher than the micron-sized MCM-41 aluminosilicates. The enhanced activity of the Al-MS nanoparticles displays the importance of textural porosity. The improvement of the catalytic activity of nano-sized mesoporous silica materials has been demonstrated for several condensed phase reactions in which access to framework reaction sites may be diffusion limited $[7,26]$. Therefore, the catalysts with better framework accessibility and connectivity are shown to be much more active for the catalytic reaction of large molecules.

Two basic concepts for creating the M-MS nanotubes or nanoparticles are: (1) A fast nucleation and growth rate leading to crystallization of small nanocrystals, and (2) Matching the condensation rate of silica and metal oxide. Based on the chemistry of silica [27], the fastest condensation rate is near neutral $(\mathrm{pH} 6.0-8.0)$. Thus, the
$\mathrm{pH}$ of the solution should be properly adjusted within the range of 8.0-9.0. Also, the interactions between the surfactant templates $\left(\mathrm{S}^{+}\right)$and silica species (I) are changed from the weak hydrogen bonding $\left(\mathrm{S}^{+} \mathrm{X}^{-} \cdots \mathrm{I}^{\circ}\right)$ in acidic solution to electrostatic interaction $\left(\mathrm{S}^{+} \mathrm{I}^{-}\right)$in alkaline ammonia solution. The strong surfactant-silica interaction would accelerate the silica condensation as well. The nuclei formed from the hydrolyzed TEOS would grow at the same time and induce the formation of the nanoparticle or nanotubes in alkaline ammonia solution.

Generally, metal ions are stable in a highly acid aqueous solution but condense fast in alkaline media because the silica condensation is fast enough at $\mathrm{pH} 8.0-9.0$ in the presence of the $\mathrm{C}_{16} \mathrm{TMAB}$ to be comparable to the rapid condensation rate of metal oxides. Consequently, the metal oxides-incorporated or grafted silica mesoporous nanoparticles with the silica/metal ratio $\geq 20$ may be productively obtained without the formation of the nano-clusters of the metal oxides at the same time.

This two-step synthetic method has been applied extensively to prepare the mesoporous silica with different pore size by using various cationic alkyltrimethylammonium surfactants (i.e. $\mathrm{C}_{n} \mathrm{TMAX}, n=12-18, \mathrm{X}=\mathrm{Cl}$ or $\mathrm{Br}$ ) as template or adding a proper amount of hydrocarbons as the pore-expender. Moreover, the mesoporous nano-catalyst with bi-, tri- or multi-reaction centers could be conveniently

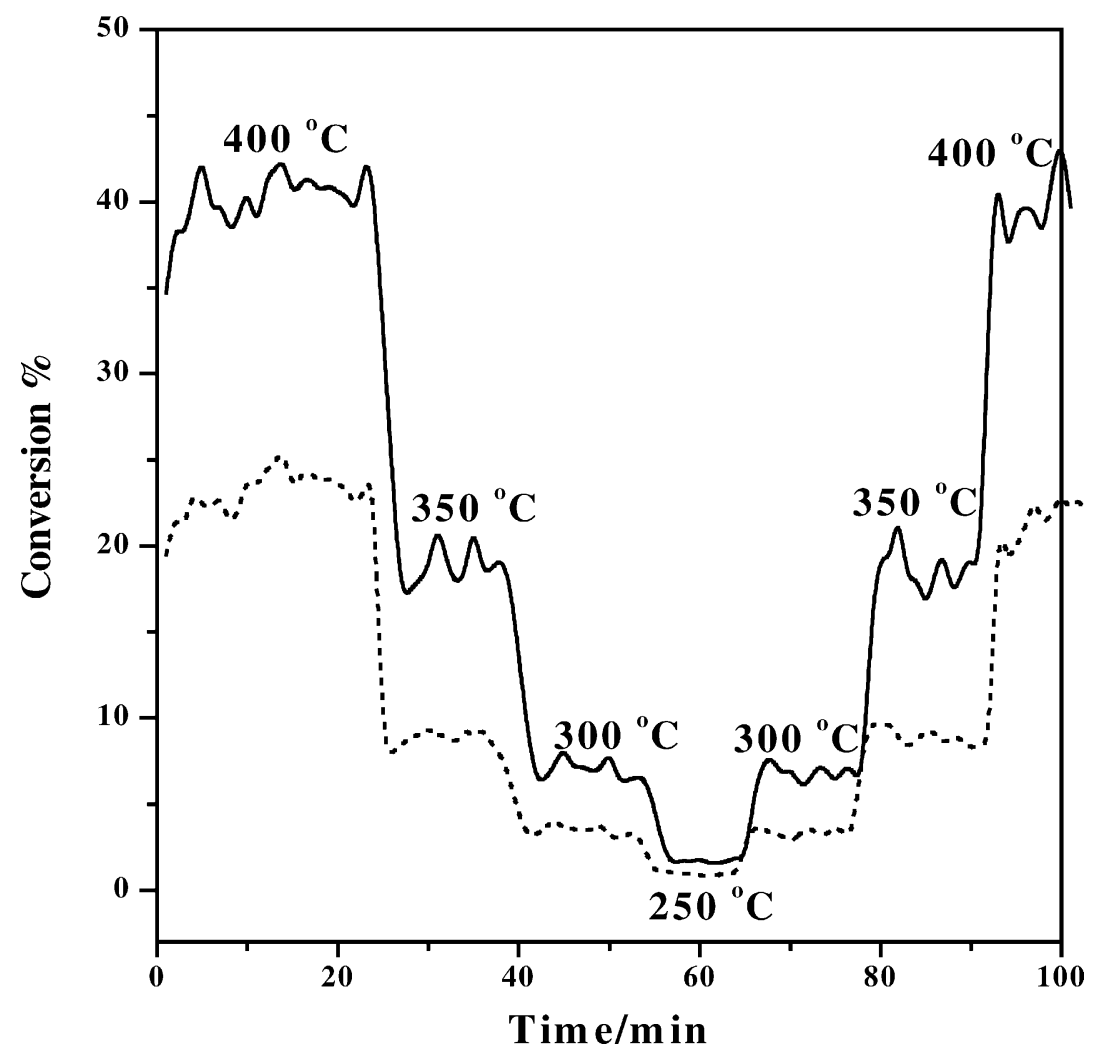

Fig. 5. Cumene conversions vs. time at different temperatures. The solid line for the Al-MS nanoparticle sample with $(\mathrm{Si} / \mathrm{Al}=20)$ and the dashed line for the MCM-41 aluminosilicate $(\mathrm{Si} / \mathrm{Al}=20)$ in micron size. Reaction conditions: flow rate: $20 \mathrm{ml} / \mathrm{min}$, carry gas: $\mathrm{N}_{2}$; cumene: saturated vapor pressure at $0{ }^{\circ} \mathrm{C}$; catalyst: $0.05 \mathrm{~g}$; a continuous flow fixed bed system at different temperatures from 250 to $400{ }^{\circ} \mathrm{C}$. The products were analyzed on-line by a Shimadzu GC-7A gas chromatograph. 
obtained performing a mixture of two, three, or more metal alkoxides or salts in the acidic solution.

\section{Conclusion}

We provided a carefully designed two-step synthetic method (pre-hydrolysis in acidic medium and co-condensation in alkaline solution) efficiently and conveniently to prepare metal-incorporated or -grafted mesoporous silica nanotubes and nanoparticles. Due to the unique properties of high-connectivity, large pores and good dispersion, the metal oxides-incorporated or -grafted mesoporous silica nanoparticles and nanotubes could be considered as highperformance nano-catalysts. The nano-sized mesoporous materials can also be used for many other catalytic applications where transportation of molecules may be a concern.

\section{Acknowledgement}

The research was financially supported by the National Science Council of Taiwan (NSC92-2113-M-006-015).

\section{References}

[1] C.T. Kresge, M.E. Leonowicz, W.J. Roth, J.C. Vartuli, J.S. Beck, Nature 359 (1992) 710.

[2] T. Yanagisawa, T. Shimizu, K. Kuroda, C. Kato, Bull. Chem. Soc. Jpn. 63 (1990) 988.

[3] D. Zhao, P. Yang, Q. Huo, B.F. Chmelka, G.D. Stucky, Curr. Opin. Solid State Mater. Sci. 3 (1998) 111.

[4] J.Y. Ying, C.P. Mehnert, M.S. Wong, Angew. Chem. Int. Ed. 38 (1999) 56
[5] Q. Huo, D.I. Margolese, G.D. Stucky, Chem. Mater. 8 (1996) 1147.

[6] H.P. Lin, C.Y. Mou, Acc. Chem. Res. 35 (2002) 927.

[7] D.R. Rolison, Science 299 (2003) 1698.

[8] H.P. Lin, S.T. Wang, C.Y. Mou, C.Y. Tang, J. Phys. Chem. B. 104 (2000) 8967.

[9] S.T. Wong, H.P. Lin, C.Y. Mou, Appl. Catal. 198 (2000) 103.

[10] T.R. Pauly, Y. Liu, T.J. Pinnavaia, S.J. Billinge, T.P. Rieker, J. Am. Chem. Soc. 12 (1999) 8835.

[11] S. Shio, A. Kimura, M. Yamaguchi, K. Yoshida, K. Kuroda, Chem. Commun. (1998) 2461.

[12] X. Wang, T. Dou, Y. Xiao, Chem. Commun. (1998) 1053.

[13] E. Matijevic, Chem. Mater. 5 (1993) 412.

[14] C.E. Fowler, D. Khushalani, B. Lebeau, S. Mann, Adv. Mater. 13 (2001) 649

[15] H.P. Lin, C.P. Tsai, Chem. Lett. 32 (2003) 1092.

[16] J.E. Haskouri, D.O. de Zárate, C. Guillem, A.B. Porter, M. Caldés, M.D. Marcos, D.B. Poter, J. Latorre, P. Amorós, Chem. Mater. 14 (2002) 4502.

[17] S. Mann, Biomineralization Principles and Concepts in Bioinorganic Materials Chemistry, Oxford University Press, 2001.

[18] S. Sadasivan, C.E. Fowler, D. Khushalani, S. Mann, Angew. Chem. Int. Ed. 41 (2002) 2151.

[19] P.C.A. Alberius, K.L. Frindell, R.C. Hayward, E.J. Kramer, G.D. Stucky, B.F. Chmelka, Chem. Mater. 14 (2002) 3284.

[20] Q. Huo, D.I. Margolesea, G.D. Stucky, Chem. Mater. 8 (1996) 1147.

[21] S.J. Gregg, K.S.W. Sing, Adsorption, in: Surface Area and Porosity, Academic Press, London, 1982.

[22] H.P. Lin, C.P. Kao, S.B. Liu, C.Y. Mou, J. Phys. Chem. B 104 (2000) 7885.

[23] M.S. Morey, S. O'Brien, S. Schwarz, G.D. Stucky, Chem. Mater. 12 (2000) 898.

[24] M.S. Morey, G.D. Stucky, S. Schwarz, M. Fröba, J. Phys. Chem. B 103 (1999) 2037.

[25] B.L. Newalkar, J. Olanrewaju, S. Komarneni, J. Phys. Chem. B 105 (2001) 8356.

[26] C.J.H. Jacobsen, C. Madsen, J. Houzvicka, I. Schmidt, A. Carlsson, J. Am. Chem. Soc. 122 (2000) 7116.

[27] R.K. Iler, The Chemistry of Silica: Solubility, Polymerization, Colloid and Surface Properties, and Biochemistry, Wiley, New York, 1979. 